\title{
Journal of Bacteriology and

\section{In Vitro Study for Comparing the Cytotoxicity of Silver and Gold Nanospheres on Raw 264.7 Murine Macrophage Cell Line}

\author{
Hala Ragab Khalil Ali ${ }^{1^{\star}}$, Moawad $\mathbf{M S}^{2}$ and Selim $\mathrm{SA}^{3}$ \\ ${ }^{1}$ Department of Microbiology and Immunology, Animal Health Research Institute (AHRI), Dokki, Egypt \\ ${ }^{2}$ Faculty of Veterinary Medicine, Department of Toxicology and Forensic Medicine, Giza, Egypt \\ ${ }^{3}$ Faculty of Veterinary Medicine, Department of Microbiology and Immunology, Giza, Egypt
}

*Corresponding author: Ali HRK, Department of Microbiology and Immunology, Animal Health Research Institute (AHRI), Dokki, Egypt, Tel: +20 33374856; E-mail: ali.hala64@yahoo.com

Received date: January 28, 2016; Accepted date: February 27, 2016; Published date: March 02, 2016

Copyright: $\odot 2016$ Ali HRK, et al. This is an open-access article distributed under the terms of the Creative Commons Attribution License, which permits unrestricted use, distribution, and reproduction in any medium, provided the original author and source are credited.

\begin{abstract}
Silver nanospheres (AgNSs) and gold nanospheres (AuNSs) made a huge commercial and scientific interests due to their antimicrobials potency, use in nanomedicine and drug delivery systems. Macrophages are the primary site for clearing waste substances from tissues and the intracellular infections produced by pathogens like Mycobacterium tuberculosis. Therefore, studying the cytotoxic effects of nanomaterials on such promising model will open new era towards safe use of nanobased treatments of intracellular pathogens. In This study, the effect of three different concentrations $(10,20,40 \mu \mathrm{g} / \mathrm{ml})$ of AuNSs and AgNSs with an average diameter of $20 \mathrm{~nm}$ was studied on RAW264.7 murine macrophage viability for 3 hours using XTT assay. AuNSs were found nontoxic to macrophages at all tested concentration. However AgNSs showed acute decline in viability of RAW264.7 cells even at the lowest concentration $(10 \mu \mathrm{g} / \mathrm{ml})$. In another experiment, the effect of AuNSs and AgNSs was examined on short and long term manners by treating macrophages with single dose of $20 \mu \mathrm{g} / \mathrm{ml}$ for different time points $(0,10,20,30,60$ minutes, 24, and 48 hours). Results revealed that AgNSs induced acute cytotoxicity to macrophages till 48 hours, while gold nanospheres were safe to RAW264.7 cells at all-time points compared to untreated control. Thus the AuNSs might represent a safe drug delivery platform for combating the intracellular pathogens like $M$. tuberculosis without hurting their host cells.
\end{abstract}

\section{Keywords: AgNSs; AuNSs; XTT}

\section{Introduction}

Recently, nanoparticles opened a broad area of interest due to their unique physical and chemical properties. They became a successful platform in a long list of useful applications including biomedicine, chemistry, food industry, cosmetics and electronics. The metal nanoparticles played the back-bone role in many medical and manufacturing industries, while silver and gold nanoparticles were of utmost interest among all metal-based nanomaterials due to their incorporation in different products. Gold nanoparticles has been attracted great interest in diagnostic and therapeutic applications, especially cancer therapy and drug delivery $[1,2]$. On the other hand, silver nanoparticles were widely incorporated in many applications such as food packaging [3], wound dressing and surgical instruments [4,5], water purification [6], and textiles [7]. Many authors have addressed the potential use of silver nanoparticles as a vehicles for antimicrobial agent $[8,9]$, while others reported the bactericidal effect of AgNPs on gram negative bacteria [10] as well gram-positive and intracellular infections [11]. The macrophages are the primary host infected by intracellular pathogens, like Mycobacterium tuberculosis (TB) and Brucella, which significantly constitute public health concerns. Unusually and professionally, these infecting intracellular pathogens can evade the hostile environment of macrophage, block the maturation of phagosome into phagolysosome, survive, and multiply inside the infected macrophages. Moreover, disease control and treatment of these pathogens became a difficult challenge due to their intracellular survival nature, and the emergence of new drug-resistant bacterial strains. Furthermore, macrophages are among the most important cellular components of innate immunity, and they are considered the main resident phagocytic cells inside all organs for clearance of any waste material in blood circulation and tissues. Not even, these cells were found to have higher capacity to internalize nanomaterials more efficiently than any other cellular types in the body [12]. So developing a nano-based drug delivery system, with high ability to target macrophages and deliver the carried antibacterial drugs inside their infected cells, could be a promising approach for fighting these pathogens and curing their caused chronic diseases. Nano-based drug delivery systems have attracted the attention of many research groups, which concluded that metal nanoparticles as gold and silver could be promising noble nanomaterials in biomedicine and drug delivery [13-15]. However the gold and silver nanoparticles have shown antimicrobial activities against Gram-negative and Grampositive bacteria [16,17], they revealed antimycobacterial activities against extracellular TB [18]. Other different nanoparticles were investigated in vitro and in vivo as drug delivery vehicle for anti-TB drugs. Kisich et al. used biodegradable nanopolymers and enhanced the efficacy of encapsulated moxifloxacin against the intracellular Mycobacterium tuberculosis infection [19], Pandey and Khuller used the liposomal nanoparticles [20], while Clemen et al. targeted $M$. tuberculosis infected macrophages through functionalized mesoperous silica nanoparticles [12]. Consequently we assume that testing silver and gold nanoparticles as drug delivery vehicle and loading them with anti-TB drugs in an attempt to target the $M$. tuberculosis infected macrophages may potentiate their efficacy against the intracellular TB 
infection. Although the nano-based drug delivery systems offer a potential advantage in accumulating drug targets inside the macrophage and reducing the systemic side effects, nanoparticles have a high binding capacity to biological molecules and can access into the mammalian tissues and cells easily. These characteristics may possibly generate adverse side effects to mammalian cells and may result in significant toxicities even if they are biochemically inert at bulk size. Thus saftey of the employed drug delivery vehicle to the infected host macrophage cells must be well tested, because if the nanoparticles were cytotoxic, the host cells will be killed and liberate the intracellular pathogens which in turn attack and infect other healthy macrophages and spread the disease rather than control and treat. From this view, RAW264.7 murine macrophage cell line was selected, as ideally suited cell model, and two metal nanoparticles, gold and silver were employed as nano-based drug delivery systems; maintaining the same physical and chemical properties as shape, size, and capping material. The aim of this study is to assess dose-dependent and time-dependent cytotoxicity of silver and gold nanospheres on RAW264.7 murine macrophage cell line using the cell viability assay (XTT) and microscopical examination. Since a current deficient knowledge of nanosized silver and gold cytotoxicity exist on RAW264.7 macrophage cells. Thus in the future, this study could contribute to scientific community, improving the selection of suitable drug delivery systems comparing between the silver and gold nanospheres, which currently are the two best options.

\section{Materials and Methods}

All chemicals were analytically pure grade from Sigma-Aldrich (St. Louis, USA). All cell culture media and reagents were from Mediatech (Tewksbury, MA, USA), while the cell scraper $18 \mathrm{~cm}$ handle $/ 1.8 \mathrm{~cm}$ blade used for sub culturing cells was from Falcon (Wiesbaden, Germany). XTT cell viability kit (Catalog number: 30007) used for cytotoxicity studies was purchased from Biotium (Hayward, CA, USA).

\section{Synthesis of gold nanospheres}

Citrated gold nanospheres (AuNSs) with an average diameter of 20 $\mathrm{nm}$ were synthesized as described by Frens [21] by the reduction of chloroauric acid with trisodium citrate. Briefly, $5 \mathrm{~mL}$ of $5 \mathrm{mM} \mathrm{HAuCl}_{4}$. $3 \mathrm{H}_{2} \mathrm{O}$ were added to $90 \mathrm{~mL}$ of deionized water (DI) and heated with continuous stirring until it began to boil. five $\mathrm{mL}$ of $0.5 \%$ trisodium citrate solution were added with continuous heating and stirring until the solution turned into wine red color, then it was kept to cool at room temperature before characterization.

\section{Synthesis of silver nanospheres}

Silver nanoparticles were synthesized by chemical reduction method as reported by Turkevich et al. [22]. Briefly, a solution of $\mathrm{AgNO}_{3}$ was used as $\mathrm{Ag}^{1+}$ ions precursor, while sodium citrate as mild reducing agent and Polyvinyl Alcohol (PVA) played the role as stabilizing agent. The color of the solution slowly turned into greyish yellow indicating the reduction of the $\mathrm{Ag}^{1+}$ ions into silver nanoparticles.

\section{Characterization of synthesized nanoparticles}

The size and shape of synthesized gold nanoparticles were characterized using transmission electron microscopy (TEM; JEOL 100CX-II, Tokyo, Japan) and UV-Vis spectrophotometer. The average particle diameters of synthesized nanoparticles were measured by processing TEM images using ImageJ software (National Institute of
Health NIH, Bethesda, MA, USA). Briefly, a drop of synthesized nanoparticles solutions was placed on carbon coated TEM copper grid and allowed to dry for 5 minutes, and then the excess solution was removed using a blotting paper. The copper grid was inserted in TEM microscope and nanoparticles images were captured for further analysis with ImageJ software. The surface plasmon resonance peaks were detected using UV-Vis spectroscopy at $520 \mathrm{~nm}$ for gold nanospheres and $420 \mathrm{~nm}$ for silver nanospheres.

\section{Macrophage cell culture}

The murine macrophage, RAW264.7 cell line were cultured in Dulbecco's Modification of Eagle's Medium (DMEM) supplemented with $4.5 \mathrm{~g} / \mathrm{L}$ glucose, L-glutamine, and sodium pyruvate, $10 \%$ fetal bovine serum, and $1 \%$ streptomycin/penicillin antibiotics. Cell cultures were kept at $37^{\circ} \mathrm{C}$ in a humidified $5 \% \mathrm{CO}_{2}$ incubator, and when confluency reached $70 \%$, cells were scraped with cell scraper $18 \mathrm{~cm}$ handle $/ 1.8 \mathrm{~cm}$ blade and subcultured.

\section{Microscopic examination}

The cells were grown in 96 well plates at $1 \times 10^{4}$ density per well for overnight, then treated with different concentration of AgNSs or AuNSs for fixed or different time points. The cell cultures were examined under inverted microscope (Olympus CKX41, Tokyo, Japan) using $10 \mathrm{x}$ or $40 \mathrm{x}$ objectives, while images of cells were captured using Samsung digital camera.

\section{Cellular viability}

To determine the effect of different concentration of AuNSs and AgNSs on RAW264.7, cells were seeded in 96 well plates at an approximate density of $1 \times 10^{4}$ cells per well for $24 \mathrm{~h}$. After 1 day, the old media was removed and replaced with new DMEM media contained $10,20,40 \mu \mathrm{g} / \mathrm{ml}$ of gold or silver nanospheres. In another experiment, the cytotoxicity of murine macrophage RAW 264.7 cells were tested after their exposure to fixed dose of $20 \mu \mathrm{g} / \mathrm{ml}$ gold or silver nanospheres for different short and long term time points $(0,10,20$, $30,60 \mathrm{~min}, 24$, and $48 \mathrm{~h}$ ). After incubation for different time points, the culture media contained nanoparticles was replaced with clear DMEM without phenol red (CDMEM) contained the XTT solution and incubated for overnight. After incubation, the intensity of color was measured as absorbance at $450 \mathrm{~nm}$ and $690 \mathrm{~nm}$ for gold and silver nanospheres consequently using Synergy H4 Multimode Plate Reader (Biotek, Winooski, VT, USA). The viability percent was compared to untreated control cells as a result of three independent experiments.

\section{Statistical analysis}

The obtained viability of RAW cells treated with NPs was compared to untreated controls using unpaired t-tests, Results are expressed as the mean \pm SE of three independent experiments. The differences between the cell viability studied were not found to be statistically significant. The level of significance was set at $\mathrm{P}<0.05$.

\section{Results}

The gold and silver nanospheres were successfully synthesized. And upon characterization AuNSs revealed significant plasmon resonance peak at $520 \mathrm{~nm}$ while the peak of silver nanoparticles was detected at $420 \mathrm{~nm}$ (Data not shown). Transmission electron microscope (TEM) confirmed and revealed the monodispersity of the synthesized 
nanoparticles with an average particle diameter of $20 \mathrm{~nm}$ for both gold and silver nanospheres (Figure 1). As the first and the most determinative effect following exposure of cell monolayer to toxic agent is the morphological alterations in the cell shape, therefore we used the optical microscope to determine cellular damage and thus, to establish an index of cytotoxicity in the model used. In a pilot experiment, RAW264.7 cells were exposed to $40 \mu \mathrm{g} / \mathrm{ml}$ of either Au or AgNSs for $3 \mathrm{~h}$ using light microscopical examination, the macrophages were severly damaged upon exposure to AgNSs and their morphology and shape significantly impaired. In contrast cells exposed to gold nanospheres were almost intact with higher viability appearance compared to cells exposed to silver nanospheres (Figure 2). For confirming the cytotoxic effect of silver nanospheres on RAW264.7 morphology, a main experiment was designed in order to include more geometrical time points and to quantify the viability result using the XTT assay. Different triplicates of RAW264.7 macrophages cells were treated for $3 \mathrm{~h}$ with three different concentrations $10,20 \& 40 \mu \mathrm{g} / \mathrm{ml}$ of negatively charged citrated AgNSs and in comparison to AuNSs. After incubation time the results revealed a significant acute cytotoxicity and decline in the viability percentage of the treated cells with all the three concentrations of AgNSs (10, $20 \& 40 \mu \mathrm{g} / \mathrm{ml}$ ) (Figure 3a and Table 1). Surprisingly, the RAW 264.7 incubated with the same concentrations of gold nanospheres showed much better viability as illustrated in figure $3 \mathrm{~b}$ and shown in table 1 . In order to examine the effect of short term and long term exposure of gold and silver nanoparticles on murine macrophage cells, the RAW264.7 cells were exposed to fixed dose of $20 \mu \mathrm{g} / \mathrm{ml}$ of either AuNSs or AgNSs for different time points $(0$, $10,20,30,60 \mathrm{~min}, 24$, and $48 \mathrm{~h}$ ) and the cells were examined microscopically. The silver nanospheres had more significant alterations in cellular growth of RAW cells during first 20 minutes since more than $50 \%$ of cell populations lost their morphological integrity and characterized by shrinkage of their cell membrane. By the end of the hour about $25 \%$ of the cells were left in the plate wells. While after 48 hours there were no viable cells found in the microscopical field and the wells appeared empty except of some cells and lots of cell debris. On the other hand, gold nanospheres did not affect the morphology and viability of RAW264.7 cells at all tested time points. The treated cells appeared healthy without any cellular alterations in growth and looked viable with intact cellular membrane as shown in (Figure 4). The XTT assay was employed to quantify the viability of treated cells and as well to confirm the result obtained by the microscopical examination. The same experiment was repeated the cells exposed to $20 \mu \mathrm{g} / \mathrm{ml}$ of AuNSs or AgNSs for different time points up to 48 hours the viability declined but in severe manner than that recorded in their first hour of exposure to record 14.26 and $9.3 \%$ after 24 and 48 hours exposure respectively (Figure 5 and Table 2).

\begin{tabular}{|l|l|l|}
\hline \multirow{2}{*}{ The concentrations } & Silver nanospheres & Gold nanospheres \\
\cline { 2 - 3 } & Viability\% & Viability\% \\
\hline Control & 100 & 100 \\
\hline $10 \mu \mathrm{g} / \mathrm{ml}$ & 43 & 94.3 \\
\hline $20 \mu \mathrm{g} / \mathrm{ml}$ & 15.7 & 91.7 \\
\hline $40 \mu \mathrm{g} / \mathrm{ml}$ & 13.5 & 87.8 \\
\hline
\end{tabular}

Table 1: The cell viability result of exposing raw macrophage cell line to three different concentrations of silver or gold nanospheres for fixed time ( $3 \mathrm{hrs}$ ).

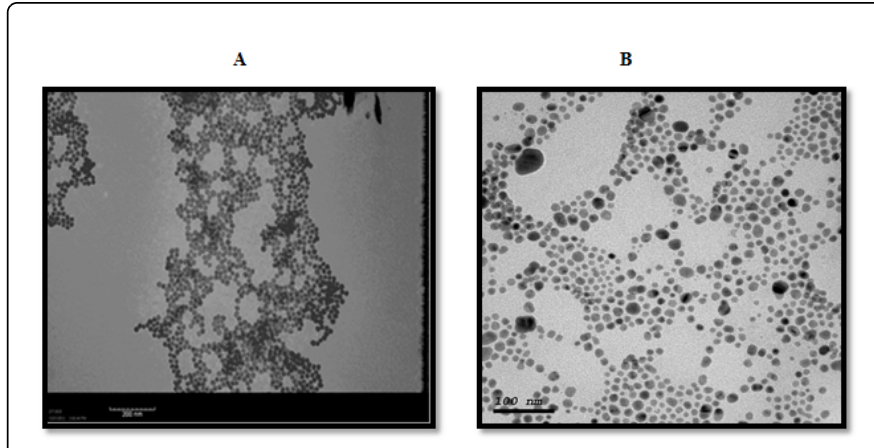

Figure 1: TEM image of gold and silver nanospheres. A. TEM image of AuNSs showed an average particle size $20 \mathrm{~nm}$ and B. TEM image of AuNSs showed an average particle size $20 \mathrm{~nm}$.

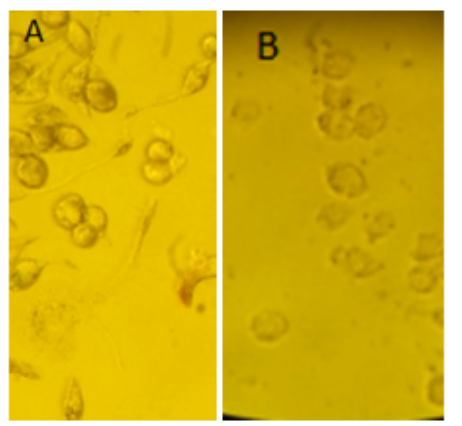

Figure 2: Microscopical observation comparing between the cytotoxic effect produced by nanoparticles on Raw 264.7 cells at high concentration $(40 \mu \mathrm{g} / \mathrm{ml})$, A. illustrating no cytotoxic effect produced after 3 hours incubation with $40 \mu \mathrm{g} / \mathrm{ml}$ of AuNSs , B. AgNSs at the same concentration and the same exposure time result in severe cell death. (10X objective).
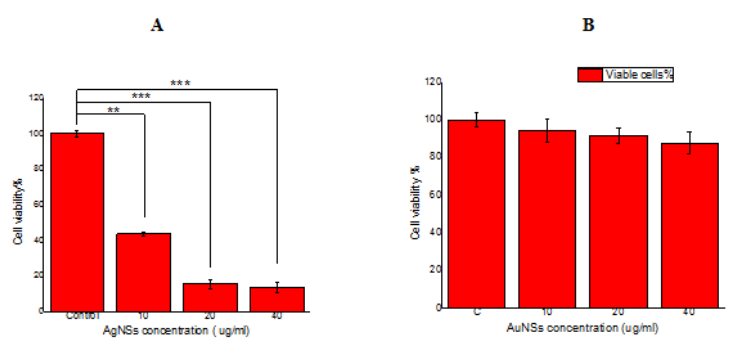

Figure 3: Cell viability Data A. Cell viability results for the exposure of RAW264.7 cell line to three different concentrations (10, 20 \& 40 $\mu \mathrm{g} / \mathrm{ml}$ of AgNSs solutions for $3 \mathrm{hr}$ ). B. After exposure to AuNSs with the same three concentration Statistical significance has been indicated by ${ }^{* *}(\mathrm{p}$-value $<0.01),{ }^{* *}(\mathrm{p}$-value $<0.001)$. 
Page 4 of 5

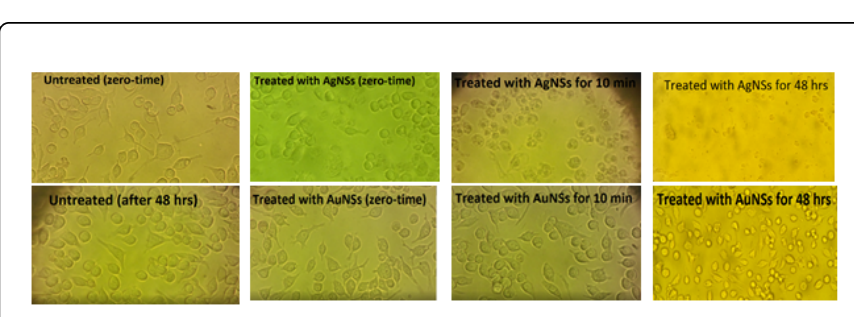

Figure 4: The microscopic images of RAW264.7 cell line treated with $20 \mu \mathrm{g} / \mathrm{ml}$ of AgNSs or AuNSs for different time points $(0,10$ min and $48 \mathrm{~h}$ ). Upper: the RAW monolayer exposed to AgNSs at zero-time showing morphological alteration, after10 min almost all the cells looks shrinked and rounded and after $48 \mathrm{~h}$. The field shows massive cell death and a lot of cell debris. Bottom: the RAW exposed to Au NSs for zero time, $10 \mathrm{~min}$ and $48 \mathrm{~h}$ are viable, healthy and showing no difference than untreated cells. NB (these images were taken by camera Samsung).

The silver nanospheres exerted severe toxicity to RAW even at zerotime point as the viability percent recorded was $78 \%$ compared to the control. After 10 minutes the viability of cells were reduced to $63.3 \%$, while after 20 and 30 minutes less than half of total number of cells/ wells were viable with viability percent 43 and $39.7 \%$. By the end of first hour, viability of cells exposed to silver nanospheres was 24.9 which indicated that one quarter of the total cells per well were viable. The result indicated that raw cells were exposed to severe cytotoxicity upon their exposure to silver nanospheres of $20 \mu \mathrm{g} / \mathrm{ml}$ concentrations within one hour. Afterwards and up to 24 and $48 \mathrm{~h}$. alternatively gold nanospheres did not exert a significant toxicity on murine macrophage even after long term exposure for 24 and $48 \mathrm{~h}$. The cellular viability of cells exposed to $20 \mu \mathrm{g} / \mathrm{ml}$ of AuNSs was $92.2 \%$ and $86.8 \%$ after 24 and $48 \mathrm{~h}$ respectively (Figure 5 and Table 2 ).

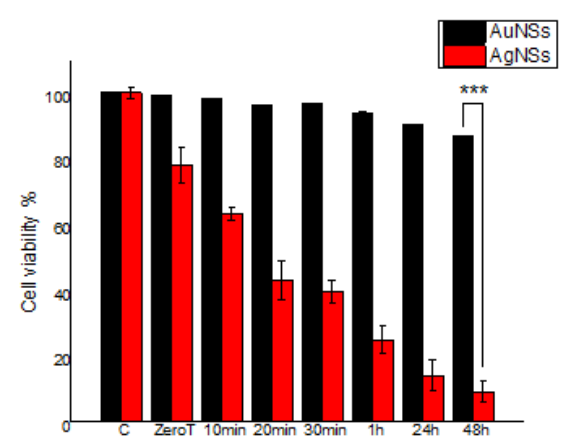

Figure 5: Viability results of RAW 264.7 cell exposure to $20 \mu \mathrm{g} / \mathrm{ml}$ AuNSs or AgNSs at different time points $(0,10,20,30 \mathrm{~min}, 1,24$ and $48 \mathrm{~h}$ ). Statistical significance has been indicated by ${ }^{* *}(\mathrm{p}-$ value $<0.001)$.

\begin{tabular}{|l|l|l|}
\hline \multirow{2}{*}{ Time points } & Silver nanospheres & Gold nanospheres \\
\cline { 2 - 3 } & Viability \% & Viability\% \\
\hline 0 & 78 & 99.2 \\
\hline
\end{tabular}

\begin{tabular}{|l|l|l|}
\hline $20 \mathrm{~min}$ & 43.2 & 96.2 \\
\hline $30 \mathrm{~min}$ & 39.7 & 96.7 \\
\hline $1 \mathrm{~h}$ & 24.9 & 93.7 \\
\hline $24 \mathrm{~h}$ & 14.2 & 92.2 \\
\hline $48 \mathrm{~h}$ & 9.3 & 86.8 \\
\hline
\end{tabular}

Table 2: Time exposure/ viability of raw macrophage exposed to fixed concentration $(20 \mu \mathrm{g} / \mathrm{ml})$ of silver or gold nanospheres for different time points.

\section{Discussion}

Taking together, the data of microscopical examination and viability assay revealed that silver nanospheres were highly toxic to RAW cell compared to their counterpart gold nanospheres at different concentration and time points. Up to our knowledge, these data might be the first results for comparing the cytotoxicity of silver and gold nanospheres on RAW 264.7 murine macrophage cell line. Haase et al. [23] showed that even the low doses of nano silver were highly toxic to human macrophage while treatment the cells with nanogold did not reveal significant toxicity even at higher concentration; the cells retained its viability up to $80 \%$ compared to control set. And Raymond et al. [24] studied the cytotoxicity of silver nanoparticles $(20 \mathrm{~nm}$ and $110 \mathrm{~nm}$ ) on different cell line including two murine primary alveolar macrophages (C57Bl/6, and MARCO), they concluded that the small size of silver nanoparticles $(20 \mathrm{~nm})$ was more toxic to all cell lines and more active with THP1 macrophage compared to larger sized silver nanoparticles $(110 \mathrm{~nm})$. In our current study, RAW264.7 macrophage cells were significantly and severly affected upon contact with silver nanospheres even at zero time with viability $78 \%$ compared to $99.2 \%$ with the counterpart gold nanospheres. Affected cells were shrinked and become more likely rounded. Arora et al. revealed that higher concentrations of AgNPs, the changed morphology of the cells attributed to the higher level of oxidative stress informs of decreased glutathione (GSH) and super oxide dismutase (SDS) and increased lipid peroxidation, which finally leads to apoptosis by increasing caspase-3 activity and DNA fragmentation [25]. Silver nanoparticles show moderate solubility and contribute silver ions upon contact with cell medium, so demonstrated cytotoxicity of silver nanospheres by microscopical examination and XTT assay might be due to the effect of instant action generated silver ions on the outer membrane of RAW 264.7 cells. The significant reduction of cellular viability at zero time point and the following $60 \mathrm{~min}$ as well the significant loss of cellular integrity under the microscope may support this assumption. Moreover, as nanoparticles internalization and accumulation inside the cells depend primarily on the incubation time with nanoparticles as stated by Trono et al. [26], the significant reduction of viability in cells exposed to AgNSs up to 10 minutes (63.3\%) is likely due to possible action of silver nanoparticles and produced ions on the outer cellular membrane of RAW cells and not because of the possible AgNPs inside cells in this short term periods. This scenario supported by Beer et al. [27] who returned the toxic effect of AgNPs to the released ion mainly than cellular internalization. In contrast, the nanogold did not induce any toxicity upto the first hour of incubation with RAW cells and only induced slight reduction of the cellular viability after long term exposure up to 24 and $48 \mathrm{~h}$. Further research investigations are needed to monitor the real time uptake of macrophages to different nanoparticles and detect the time and site of localization of the 
internalized nanoparticles as well the mechanisms of the action behind nanotoxicity of different nanoparticles to macrophages.

\section{Conclusion}

The gold nanospheres might be ideally suited as a safe drug delivery system especially for antimicrobial drugs against intracellular infections like $M$. tuberculosis (TB). They may selectively target the infected macrophages more efficiently and safely than silver nanoparticles. Our next research shall investigate the efficacy of gold nanoparticles as a drug delivery system for anti-tuberculosis drugs against intracellular TB infection. On the other hand, we will investigate the mechanism of action of silver nontoxicity on macrophages through real time monitoring of their uptake and intracellular localization.

\section{Acknowledgements}

The authors acknowledge Prof. Dr. Rafeek Soliman from Microbiology and Immunology Department for permission to use his tissue culture unit and all its facilities. As well, authors acknowledge Science and Technology Development Fund (STDF; Cairo, Egypt) for the financial support of this study.

\section{References}

1. Giljohann DA, Seferos DS, Daniel WL, Massich MD, Patel PC, et al (2010) Gold nanoparticles for biology and medicine. Angew Chem Int Ed Engl 49: 3280-3294.

2. Huang X, Jain PK, El-Sayed IH, El-Sayed MA (2007) Gold nanoparticles: interesting optical properties and recent applications in cancer diagnostics and therapy. Nanomedicine (Lond) 2: 681-693.

3. Cheng D, Yang J, Zhao Y (2004) Antibacterial materials of silver nanoparticles application in medical appliances and appliances for daily use. Chin Med Equip J 4: 26-32.

4. Cohen MS, Stern JM, Vanni AJ, Kelley RS, Baumgart E, et al. (2007) In vitro analysis of a nanocrystalline silver-coated surgical mesh. Surg Infect (Larchmt) 8: 397-403.

5. Lee HY, Park HK, Lee YM, Kim K, Park SB (2007) A practical procedure for producing silver nanocoated fabric and its antibacterial evaluation for biomedical applications. Chem Commun (Camb) 28: 2959-2961.

6. Dubas ST, Kumlangdudsana P, Potiyaraj P (2006) Layer-by-layer deposition of antimicrobial silver nanoparticles on textile fibers. Colloids and Surfaces A: Physicochemical and Engineering Aspects 289: 105-109.

7. Jain P, Pradeep T (2005) Potential of silver nanoparticle-coated polyurethane foam as an antibacterial water filter. Biotechnol Bioeng 90: 59-63.

8. Morones JR, Elechiguerra JL, Camacho A, Holt K, Kouri JB, et al. (2005) The bactericidal effect of silver nanoparticles. Nanotechnology 16 2346-2353.

9. Kim JS, Kuk E, Yu KN, Kim JH, Park SJ, et al. (2007) Antimicrobial effects of silver nanoparticles. Nanomedicine: Nanotechnology, Biology and Medicine 3: 95-101.

10. Sondi I, Salopek-Sondi B (2004) Silver nanoparticles as antimicrobial agent: a case study on E.coli as a model for Gram-negative bacteria. J Colloid Interface Sci 275: 177-182.
11. Alizadeh H, Saloute M, Shapouri R (2013) Intramacrophage antimicrobial effect of silver nanoparticles against Brucella melitensis 16M. Nanotechnology 20: 1035-1038.

12. Clemens DL, Lee BY, Xue M, Thomas CR, Meng H, et al. (2012) Targeted intracellular delivery of antituberculosis drugs to Mycobacterium tuberculosis-infected macrophages via functionalized mesoporous silica nanoparticles. Antimicrob. Agents Chemother 56: 2535-2545.

13. Fayaz AM, Girilal M, Mahdy SA, Somsundar SS, Venkatesan R, et al. (2011) Vancomycin Bound Biogenic Gold Nanoparticles: A Different Perspective for Development of Anti VRSA Agents. Process Biochem 46: 636-641.

14. Rai A, Prabhune A, Perry CC (2010) Antibiotic Mediated Synthesis of Gold Nanoparticles with Potent Antimicrobial Activity and Their Application in Antimicrobial Coatings. J Mater Chem 20: 6789-6798.

15. Tantra R, Knight A (2011) Cellular uptake and intracellular fate of engineered nanoparticles: a review on the application of imaging techniques. Nanotoxicology 5: 381-392.

16. Li X, Robinson SM, Gupta A, Saha K, Jiang Z, et al. (2014) Functional Gold Nanoparticles as Potent Antimicrobial Agents against Multi-DrugResistant Bacteria. ACS Nano 8: 10682-10686.

17. Song HY, Ko KK, Oh IH, Lee BT (2006) Fabrication of silver nanoparticles and their antimicrobial mechanisms. Eur Cells Mater 11: 58.

18. Zhou Y, Kong Y, Kundu S, Cirillo JD, Liang H (2012) Antibacterial activities of gold and silver nanoparticles against Escherichia coli and bacillus Calmette-Guérin. J Nanobiotechnology 10: 19-28.

19. Kisich KO, Gelperina S, Higgins MP, Wilson S, Shipulo E, et al. (2007) Encapsulation of moxifloxacin within poly (butyl cyanoacrylate) nanoparticles enhances efficacy against intracellular Mycobacterium tuberculosis. Int J Pharm 345: 154-162.

20. Pandey R, Sharma S, Khuller GK (2004) Nebulization of liposome encapsulated antitubercular drugs in guinea pigs. Int J Antimicrob Agents 24: 93-94.

21. Frens G (1973) Controlled nucleation for the regulation of the particle size in monodisperse gold suspensions. Nat Phys Sci 241: 20-22.

22. Turkevich J, Stevenson PC, Hillier J (1951) A study of the nucleation and growth processes in the synthesis of colloidal gold. Discuss Faraday Soc 11: 55-75.

23. Haase A, Tentschert J, Jungnickel H, Graf P, Mantion A, et al. (2011) Toxicity of silver nanoparticles in human macrophages: uptake, intracellular distribution and cellular responses. In Journal of Physics: Conference Series 304: 012030.

24. Hamilton RF, Buckingham S, Holian A (2014) The effect of size on Ag nanosphere toxicity in macrophage cell models and lung epithelial cell lines is dependent on particle dissolution. Int J Mol Sci 15: 6815-6830.

25. Arora S, Jain J, Rajwade JM, Paknikar KM (2008) Cellular responses induced by silver nanoparticles: In vitro studies. Toxicol Lett 179: 93-100.

26. Trono JD, Mizuno K, Yusa N, Matsukawa T, Yokoyama K, et al. (2011) Size, concentration and incubation time dependence of gold nanoparticle uptake into pancreas cancer cells and its future application to X-ray drug delivery system. 52: 103-109.

27. Beer C, Foldbjerg R, Hayashi Y, Sutherland DS, Autrup H (2012) Toxicity of silver nanoparticles-nanoparticle or silver ion? Toxicol Lett 208: 286-292. 